\title{
Non-ST-Elevation Acute Coronary Syndrome and Predictors of Severity Coronary Artery Disease at the Oran University Hospital Center (Algeria)
}

\author{
Boukerche $\mathrm{F}^{1,2}$, Ali $\mathrm{AA}^{3,4^{*}}$, and Hammou $\mathrm{L}^{1,2}$ \\ ${ }^{1}$ Department of Cardiology, Oran University Hospital Center, Oran, Algeria \\ ${ }^{2}$ Faculty of Medicine, Oran, Algeria \\ ${ }^{3}$ Department of Cardiology, Renaissance University Hospital Center, N'Djamena, Chad \\ ${ }^{4}$ Faculty of Human Health Sciences of N'Djamena, N'Djamena, Chad
}

*Correspondence: Adam Ahamat Ali, Department of Cardiology, Renaissance University Hospital Center, N'Djamena, Chad

Received on 02 May 2020; Accepted on 29 May 2020; Published on 03 June 2020

Copyright (C) 2020 Boukerche F, et al. This is an open access article and is distributed under the Creative Commons Attribution License, which permits unrestricted use, distribution, and reproduction in any medium, provided the original work is properly cited.

\begin{abstract}
Introduction: Non-ST-elevation (NSTE) acute coronary syndrome (ACS) is a common and polymorphic condition. Predicting significant coronary artery disease (CAD) is sometimes difficult. The objective of this study was to identify predictors of CAD severity in patients with non-ST-elevation acute coronary syndrome (NSTE-ACS).

Patients and Methods: We prospectively evaluated 296 patients with NSTE-ACS who underwent a coronary angiography. Significant $C A D$ was defined as $\geq 70 \%$ stenosis in at least one major coronary artery. Clinical characteristics in the hospital for 30 days and one-year outcomes were prospectively noted and a multivariate analysis was performed.

Results: The study included 296 NSTE-ACS patients. The mean age of the patients was $62.1 \pm$ 12.6 years old while $58.1 \%$ of the patients were males. A multivariable analysis for the significant CAD predictors is shown (Figure 1), representing current smoking (ORa $=4.4 ; 95 \%$ confidence interval $[C I]=1.5-13.0, p=0.007)$, a diabetic under insulin (Ora $=6.4 ; 95 \%[C I]=$ 2.4-17.4, $\left.p<10^{-3}\right)$, typical angina $(\mathrm{ORa}=5.4 ; 95 \%[C I]=1.7-16.8, p=0.003)$, persistent angina $(O R a=5.3 ; 95 \%[C I]=1.3-21.8, p=0.019)$, recurrence of angina $(O R a=8.9 ; 95 \%$ $[C I]=1.5-51.4 ; p=0.015)$, down sloping ST depression $(O R a=6.1 ; 95 \%[C I]=2.4-15.3, p$ $\left.<10^{-3}\right)$, positive troponin $\left(\mathrm{ORa}=4.2 ; 95 \%[\mathrm{CI}]=1.9-9.2, \mathrm{p}\left\langle 10^{-3}\right)\right.$, kinetic disorder $>2$ segments $(O R a=2.5 ; 95 \%[C I]=1.1-6.0, p=0.049)$, intima-media thickness $(I M T)>0.8 \mathrm{~mm}$ $\left(\mathrm{OR} a=5.2 ; 95 \%[C I]=2.3-12.1, p<10^{-3}\right)$.

Conclusion: In this study, the severity of CAD was predicted by parameters such as typical or recurrent angina pectoris, current smoking, diabetic on insulin, down sloping ST depression, elevation of troponin, kinetic anomaly in more than two segments and the IMT greater than 0.8 mm.
\end{abstract}


Keywords: predictors, coronary artery disease, non-ST-elevation acute coronary syndrome, Oran, Algeria

Abbreviations: NSTE: non-ST elevation; ACS: acute coronary syndrome; CAD: coronary artery disease; CI: confidence interval; IMT: intima-media thickness; MACCE: major adverse cardiovascular and cerebrovascular events

\section{Introduction}

Acute coronary syndrome (ACS) is a leading cause of death worldwide. The diagnosis and prediction of coronary artery disease (CAD) severity in non-ST elevation ACS (NSTE-ACS) with unstable angina and NSTE myocardial infarction, can be challenging. Cardiac biomarkers, electrocardiography, the symptoms, and cardiac risk factors are all used to diagnose NSTE-ACS [1] and make subsequent decisions on the need for invasive diagnostic studies. Despite risk stratification, $14 \%$ to $20 \%$ of patients undergoing cardiac catheterization are found to have normal or non-significant CAD [2, 3]. CAD is constantly increasing in our context. This is probably linked to the change in lifestyle of the population which favors the occurrence of chronic diseases such as diabetes and hypertension. The coronary angiography purpose in NSTE-ACS is to identify and revascularize significant CAD for the improvement of the outcome. A multitude of study groups have developed risk scores to assess patients' risk of death or major adverse events [4-6]. The objective of this study was to identify predictors of CAD severity in patients with NSTEACS.

\section{Patients and Methods}

\section{Study population}

Patients were enrolled between November 01, 2015 and October 31, 2016 in the cardiology department located in Oran, north-west of Algeria. Patients aged $\geq 18$ years who were admitted in the hospital with NSTE-ACS were eligible to participate. Those with symptoms precipitated by a secondary comorbidity (e.g., anemia, heart failure, and noncardiac trauma) and patients who were participating in concomitant clinical trials were excluded. Significant stenosis is defined by narrowing $\geq 70 \%$ in at least one major coronary artery and $50 \%$ stenosis for the left artery main. Clinical characteristics in the hospital, a 30 day and a one-year outcome [major adverse cardiovascular and cerebrovascular events (MACCE)] have been studied. MACCE combined the end point of death, myocardial infarction and stroke. A one-year end point was the cause of death. This study has been approved by the management of the hospital, and all patients were provided with a signed informed consent.

\section{Statistical analysis}

Statistical analysis was performed in the 5\% significant level, either using 2 sided tests' or 2 sided CIs. Continuous data was given as the mean and range. Categorical data was summarized using counts and percentages. Logistic regression was performed to test the impact of covariates (e.g., patient characteristics, risk factors, Killip class, risk scores, cardiac biomarkers and angiographic finding) on outcome events. For this analysis, variables were selected as covariates based on a univariate analysis with a significant threshold of 0.20 , and all the factors that were chosen in this selection process were included in a step-wise logistic regression model. For the final model, odds ratios and $95 \%$ care were given. Data were analyzed with the IBM SPSS Statistics 23 . The results were expressed as mean \pm standard deviation, percentages and tabulated. To compare the results, the proportional test for the relative risk calculation and the chi-square test $\left(\chi^{2}\right)$ were used. The threshold of significance was set at $p<0.05$.

\section{Results}

The study included 296 NSTE-ACS patients. The mean age of the patients was $62.1 \pm 12.6$ years old and $58.1 \%$ of the patients were males. $58.8 \%$ of the patients had a final diagnosis of NST-segment elevation myocardial infarction (NSTEMI). 
208 patients had significant CAD and 78 non-significant CAD. Patients with significant CAD had a higher average age (63.3 vs. 58.7) and more often than not male, with a history of coronary artery disease, several cardiovascular risk factors (smoking, diabetes) and higher risk scores (GRACE, TIMI, heart) (Table 1). They had more recurrent and persistent angina, electrocardiogram ST depression and higher troponin levels (Table 2).

\section{Predictors of significant coronary artery disease}

Multivariable analysis for significant CAD predictors is shown (Figure 1), presenting currently smoking, diabetes mellitus under insulin, typical angina, persistent angina, recurrence of angina, downsloping ST depression, positive troponin, kinetic disorder $>2$ segments at the echocardiography and IMT $>0.8 \mathrm{~mm}$ were correlated with significant CAD. Furthermore, we found that 24\% (50/208) of patients with significant CAD had a low GRACE score on admission.

Using the ROC curve to compare the ability of the different risk scores (Grace, TIMI and heart scores) with our model risk score (from the multivariate analysis). This model of risk showed the highest concordance despite other risk scores followed by the heart score then TIMI and Grace score (Figure 2).

Patients with significant CAD had more hospital complications and a longer length of stay in the hospital. The 30 day to one-year follow-up showed a higher frequency of readmission rates, MACCE occurrence and mortality (Table 2).

\begin{tabular}{|c|c|c|c|}
\hline Variable & $\begin{array}{l}\text { Significant CAD } \\
\mathbf{N}=208\end{array}$ & $\begin{array}{l}\text { Non-significant CAD } \\
\mathbf{N}=\mathbf{7 8}\end{array}$ & $\mathbf{P}$ \\
\hline Mean age (year) & 63.3 & 58.7 & 0.005 \\
\hline Sex male $(\%)$ & 65.1 & 38.5 & $10^{-3}$ \\
\hline Body mass index $\left(\mathrm{kg} / \mathrm{m}^{2}\right)$ & 27.6 & 29.4 & 0.004 \\
\hline Ankle-brachial index $<0.9(\%)$ & 15.6 & 2.6 & $10^{-3}$ \\
\hline IMT (mm) & 0.87 & 0.75 & $10^{-3}$ \\
\hline Currently smoking $(\%)$ & 29.8 & 16.7 & 0.025 \\
\hline Hypertension (\%) & 56.4 & 51.3 & 0.507 \\
\hline Hypercholesterolaemia $(\%)$ & 42.7 & 32.1 & 0.108 \\
\hline Diabetes mellitus (\%) & 52.3 & 33.3 & 0.005 \\
\hline Diabetes mellitus under insulin (\%) & 35.8 & 10.3 & $10^{-3}$ \\
\hline Number of risk factors & 2.8 & 2.4 & 0.033 \\
\hline GRACE score $>140(\%)$ & 42.2 & 19.2 & $10^{-3}$ \\
\hline TIMI score $\geq 5(\%)$ & 34.9 & 9.0 & $10^{-3}$ \\
\hline Heart score $\geq 8(\%)$ & 56.9 & 12.8 & $10^{-3}$ \\
\hline Previous MI & 22.9 & 9.0 & 0.007 \\
\hline Previous PCI & 8.3 & 1.3 & 0.031 \\
\hline Previous CABG & 1.4 & 0 & 0.576 \\
\hline Typical angina (\%) & 95.9 & 66.7 & $10^{-3}$ \\
\hline Recurrent angina (\%) & 26.1 & 2.6 & $10^{-3}$ \\
\hline Persistent angina (\%) & 22.0 & 5.1 & $10^{-3}$ \\
\hline
\end{tabular}

Table 1: Patients characteristics. IMT: intima-media thickness; MI: myocardial infarction; PCI: percutaneous coronary intervention; CABG: coronary artery bypass graft. "TIMI major bleeding. 


\begin{tabular}{|c|c|c|c|}
\hline Settings & $\begin{array}{l}\text { Significant CAD } \\
\mathbf{N}=\mathbf{2 0 8}\end{array}$ & $\begin{array}{l}\text { Non-significant CAD } \\
\mathbf{N}=\mathbf{7 8}\end{array}$ & $\mathbf{P}$ \\
\hline \multicolumn{4}{|l|}{ Ischaemic ECG changes (\%) } \\
\hline ST-segment depression & 75.7 & 59.0 & 0.008 \\
\hline ST-segment modifications & 68.8 & 37.2 & $10^{-3}$ \\
\hline Down sloping ST-depression & 51.4 & 12.8 & $10^{-3}$ \\
\hline Transient ST-elevation & 8.7 & 3.8 & 0.211 \\
\hline \multicolumn{4}{|l|}{ Biological profile } \\
\hline Positive troponin $(\%)$ & 70.6 & 25.6 & $10^{-3}$ \\
\hline Mean Us T troponin ng/l & 500.9 & 148.8 & 0.006 \\
\hline Mean creatinine (blood) mg/l & 10.4 & 9.7 & 0.143 \\
\hline Mean HBA1c $\%$ & 7.0 & 6.2 & $10^{-3}$ \\
\hline Mean NT pro BNP ng/l & 610.5 & 258.1 & $10^{-3}$ \\
\hline WBC count & 8486 & 7660 & 0.045 \\
\hline Mean Hs CRP mg/l & 10.1 & 7.4 & 0.277 \\
\hline \multicolumn{4}{|l|}{ Echocardiography } \\
\hline $\operatorname{LVEF}(\%)$ & 60.5 & 54.3 & $10^{-3}$ \\
\hline Kinetic disorder (\%) & 67.4 & 32.1 & $10^{-3}$ \\
\hline \multicolumn{4}{|c|}{ Clinical outcomes up to one-year (\%) } \\
\hline Hospital complications & 18.3 & 7.7 & 0.028 \\
\hline Major bleeding & 2.3 & 2.6 & 0.590 \\
\hline Hospital admission (median; H) & 130 & 94 & $10^{-3}$ \\
\hline Hospital mortality & 1.8 & 0 & 0.576 \\
\hline Rehospitalization & 16.5 & 0 & $10^{-3}$ \\
\hline Mortality in 30 days & 3.2 & 0 & 0.196 \\
\hline MACCE in 30 days & 6.9 & 0 & 0.014 \\
\hline Mortality in one-year & 7.3 & 0 & 0.008 \\
\hline MACCE in one-year & 17.9 & 0 & $10^{-3}$ \\
\hline
\end{tabular}

Table 2: Electrocardiogram (ECG), laboratory test results and clinical outcomes. LVEF: left ventricular ejection fraction; WBC: white blood cells; MACCE: major adverse cardiovascular and cerebrovascular events.

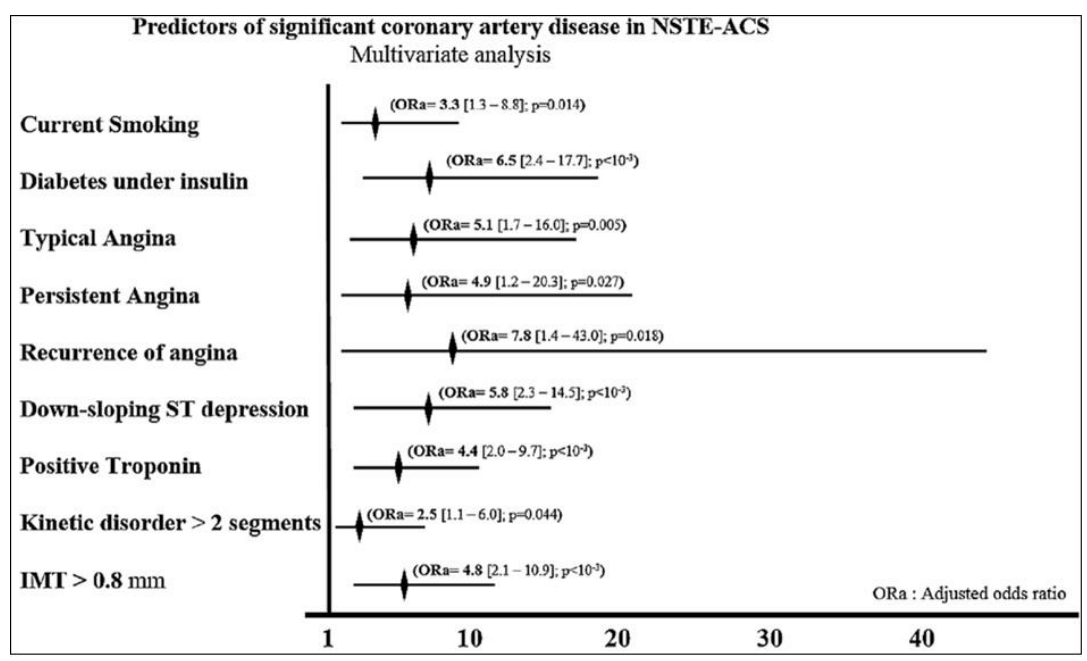

Figure 1: Multivariable analysis for predictors of significant CAD. 


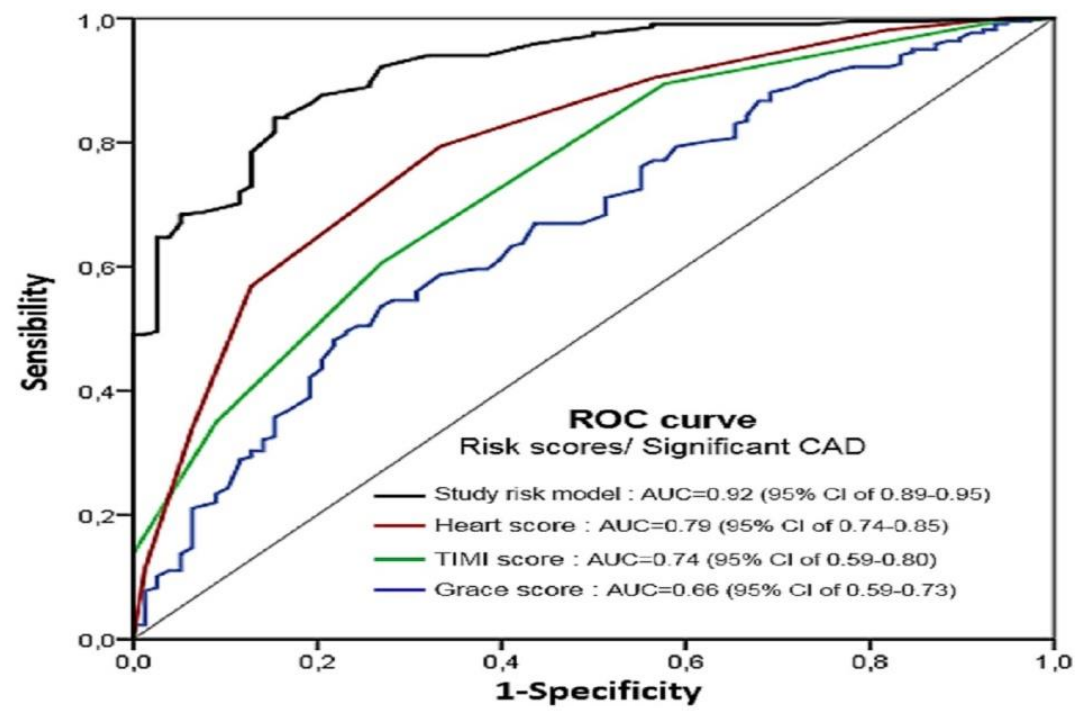

Figure 2: ROC curve to compare the ability of the different risk scores with our model risk score.

\section{Comments}

The main conclusions of this study were that the significant CAD in NSTE-ACS patients can be predicted by a set of clinical, cardiac, electrocardiographic and echocardiographic biomarker parameters. Thus, we identified 9 independent risk factors to predict the presence of a significant CAD: typical angina pectoris, recurrent angina pectoris, persistent angina pectoris, current smoking, insulin diabetes, positive troponin, ST depression downhill, kinetic disturbance in more than two segments and IMT at $0.8 \mathrm{~mm}$. Among these factors, current smoking and insulindependent diabetes have the strongest correlation with significant CAD. At 30 days and one-year, patients with significant CAD have a higher mortality and complications rate than those who do not.

NSTE-ACS includes a clinical spectrum from unstable angina to NSTE myocardial infarction [7]. The pathophysiological mechanism is a rupture of the atherosclerotic plaque and different degrees of associated thrombosis and distal embolization [8, 9]. It is accompanied by a high mortality rate, hence the development of different risk scores (e.g., GRACE, TIMI, heart) by learned societies (ESC and ACC/AHA guidelines) to assess the risk of mortality and cardiovascular complications in order to define a precocious strategy (antithrombotic and invasive) and improve the prognosis. The early invasive strategy is recommended for high risk patients [10-13]. However, these scores are not established to predict significant CAD. In view of these data, some authors have sought to establish the link between the presence of significant CAD and clinical and paraclinical parameters [10, 14]. Beigel et al. [15] were able to identify, out of 2193 patients, 5 independent parameters (peripheral vascular disease, GRACE score of > 140, chronic renal failure, prior angina, and hyperglycemia on admission) predicting the coronary anatomy at high risk. Another study done by Patel et al. [14] revealed on the analysis of 215 patients that peripheral vascular disease, chronic renal failure and previous heart failure were independent predictors of significant CAD.

Although the scores remain important tools in practice for sorting patients at high risk for cardiovascular event(s), other elements are to be taken into account to identify important CAD as we showed our results and those of Beigel et al. [15]. The use of imaging tools as transthoracic echocardiography to evaluate LVEF (Simpson method), the heart segments kinetics and measuring of the IMT improve the risk assessment of NSTE-ACS patients.

\section{Limitations}

The study was conducted in one center with a small sample of patients. Further studies in the future seem necessary to arrive at results with greater reliability. 


\section{Conclusion}

In this study, the severity of CAD was predicted by parameters such as typical or recurrent angina pectoris, current smoking, diabetic on insulin, down sloping ST depression, elevation of troponin, kinetic anomaly in more than two segments and the IMT greater than $0.8 \mathrm{~mm}$.

\section{Conflicts of Interest}

The authors declare no conflicts of interest.

\section{References}

1. Jneid H. The 2012 ACCF/AHA focused update of the unstable angina/non-ST-elevation myocardial infarction (UA/NSTEMI) guideline: a critical appraisal. Methodist Debakey Cardiovasc J. 2012;8(3):26-30.

2. Diver DJ, Bier JD, Ferreira PE, et al. Clinical and arteriographic characterization of patients with unstable angina without critical coronary arterial narrowing (from the TIMI-IIIA Trial). Am J Cardiol. 1994;74(6):531-37.

3. Mehta SR, Cannon CP, Fox KA, et al. Routine vs selective invasive strategies in patients with acute coronary syndromes: a collaborative meta-analysis of randomized trials. JAMA. 2005;293(23):2908-17.

4. Boersma E, Pieper KS, Steyerberg EW, et al. Predictors of outcome in patients with acute coronary syndromes without persistent ST-segment elevation. Results from an international trial of 9461 patients. Circulation. 2000;101(22):2557-67.

5. Antman EM, Cohen M, Bernink PJ, et al. The TIMI risk score for unstable angina/non-ST elevation MI: A method for prognostication and therapeutic decision making. JAMA. 2000;284(7):835-42.

6. Granger CB, Goldberg RJ, Dabbous O, et al. Predictors of hospital mortality in the global registry of acute coronary events. Arch Intern Med. 2003;163(19):2345-53.

7. Fitchett DH, Borgundvaag B, Cantor W, et al Non-ST segment elevation acute coronary syndromes: A simplified risk-oriented algorithm. Can J Cardiol. 2006;22(8):663-77.

8. Davies MJ. The contribution of thrombosis to the clinical expression of coronary atherosclerosis. Thromb Res. 1996;82(1):1-32.

9. Davies MJ. Stability and instability: two faces of coronary atherosclerosis. The Paul Dudley White lecture 1995. Circulation. 1996;94(8):2013-20.

10. Roffi M, Patrono C, Collet JP, et al. 2015 ESC Guidelines for the management of acute coronary syndromes in patients presenting without persistent ST-segment elevation: task force for the management of acute coronary syndromes in patients presenting without persistent ST-segment elevation of the European Society of Cardiology (ESC). European Heart Journal. 2016;37(3):267-315.

11. Morrow DA, Cannon CP, Rifai N, et al. Ability of minor elevations of troponins I and T to predict benefit from an early invasive strategy in patients with unstable angina and non-ST elevation myocardial infarction: results from a randomized trial. JAMA. 2001;286(19):2405-12. 
12. Bavry AA, Kumbhani DJ, Rassi AN, et al. Benefit of early invasive therapy in acute coronary syndromes: a meta-analysis of contemporary randomized clinical trials. J Am Coll Cardiol. 2006;48(7):1319-25.

13. Mega JL, Morrow DA, Sabatine MS, et al. Correlation between the TIMI risk score and high-risk angiographic findings in non-ST-elevation acute coronary syndromes: observations from the platelet receptor inhibition in ischemic syndrome management in patients limited by unstable signs and symptoms (PRISMPLUS) trial. Am Heart J. 2005;149(5):846-50.

14. Patel C, Prajapati J, V Patel I, et al. Predictors of the extent and severity of coronary artery disease for prognosis of patients with non-ST-segment elevation acute coronary syndromes. Int J Cardiovasc Pract. 2018;3(4):74-79.

15. Beigel R, Matetzky S, Gavrielov-Yusim N, et al. Predictors of high-risk angiographic findings in patients with non-ST-segment elevation acute coronary syndrome. Catheter Cardiovasc Interv. 2014;83(5):677-83. 